\title{
New data on the morphology of Iheringascaris inquies (Linton, 1901) (Nematoda: Anisakidae), a specific parasite of the marine fish Rachycentron canadum (Linnaeus), as revealed by SEM
}

\author{
František Moravec $^{1}$, Justin Yost $^{2}$ and Isaure de Buron ${ }^{3}$ \\ ${ }^{1}$ Institute of Parasitology, Biology Centre of the Academy of Sciences of the Czech Republic, Branišovská 31, 37005 České \\ Budějovice, Czech Republic; \\ ${ }^{2}$ Marine Finfish Division, Marine Resources Research Institute, Department of Natural Resources, 217 Fort Johnson Road, \\ Charleston, South Carolina 29422, USA; \\ ${ }^{3}$ Department of Biology, College of Charleston, 58 Coming Street, Charleston, South Carolina 29401, USA
}

\begin{abstract}
Specimens of the type species of the ascaridoid genus Iheringascaris Pereira, 1935, I. inquies (Linton, 1901) (Anisakidae), were collected from the digestive tract and mesentery of its type host Rachycentron canadum (Linnaeus) (Rachycentridae, Perciformes) from off the Atlantic coast of South Carolina, USA, during May of 2011. Scanning electron microscopical examination, used for the first time for specimens originating from the West Atlantic, made it possible to study in detail some taxonomically important morphological features, such as the number and distribution of male caudal papillae, cephalic and cuticular structures, deirids and cloacal (anal) lips. The allocation of other, poorly described, species from different hosts in Indian waters to this genus needs to be confirmed.
\end{abstract}

Keywords: fish host, marine fish, morphology, North America, parasitic nematode

The nematode Iheringascaris inquies (Linton, 1901) is a specific parasite of the digestive tract of a widely distributed marine fish, the cobia Rachycentron canadum (Linnaeus) (Rachycentridae, Perciformes). It is the type species of the genus Iheringascaris Pereira, 1935. This nematode was originally described as Ascaris inquies by Linton (1901) from off Woods Hole, Massachusetts, USA and has been reported from $R$. canadum in the West Atlantic (off the USA and Brazil), the Gulf of Mexico, and the Indian Ocean (off Pakistan, India and the east coast of Australia) (Deardorff and Overstreet 1981, Bruce and Cannon 1989). Rasheed (1965) provided a relatively good description of this species based on specimens from R. canadum off Pakistan.

However, the most complete redescription of I. inquies, based on the light microscopical examination of specimens originating from the Gulf of Mexico, was provided by Deardorff and Overstreet (1981), who resurrected Iheringascaris Pereira, 1935, previously considered a synonym of Contracaecum Railliet et Henry, 1912 or Thynnascaris Dollfus, 1933 (= syn. of Hysterothylacium Ward et Magath, 1917) by Mozgovoy (1953) and Hartwich (1974), respectively. Deardorff and Overstreet (1981) distinguished Iheringascaris from Hysterothylacium on the basis of the cuticle with conspicuous, distinctly overlapping

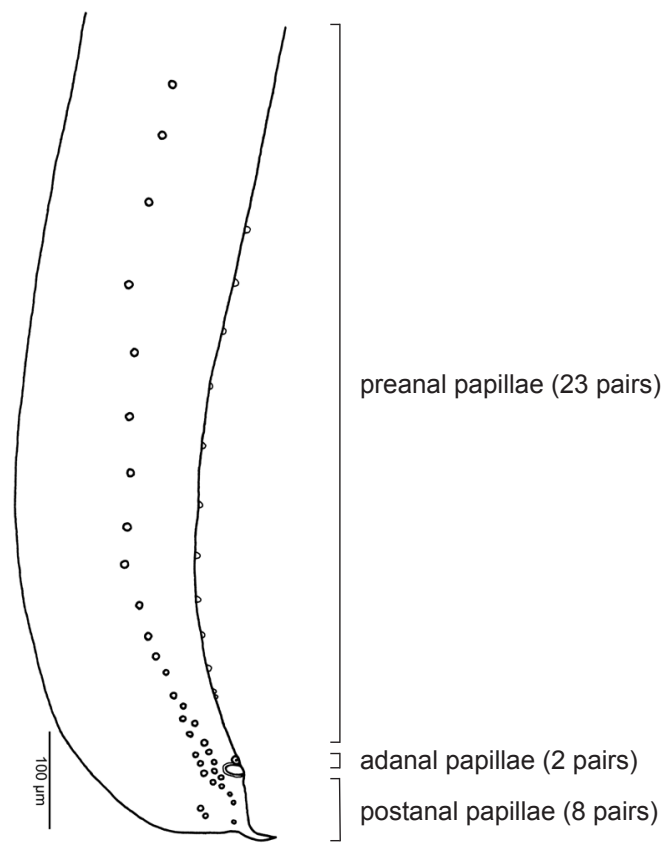

Fig. 1. Iheringascaris inquies (Linton, 1901), distribution of papillae on posterior end of male, subventral view (reconstructed from SEM micrographs).

annulations and the presence of an additional two lateral rows of caudal papillae on the posterior end of the male. According to Bruce and Cannon (1989), the two genera are also separated by the shape of the excretory system (posteriorly bilateral vs. unilateral) and the presence of distinct distal margins to the interlabial and lip peduncles in Iheringascaris (absent in Hysterothylacium).

On 13th May of 2011, a four year old female specimen of $R$. canadum measuring $1.15 \mathrm{~m}$ in total length and weighing $14 \mathrm{~kg}$ was caught by a local fisherman off Charleston Harbor, South Carolina, USA and was found infected by helminth para-

Address for correspondence: F. Moravec, Institute of Parasitology, Biology Centre of the Academy of Sciences of the Czech Republic, Branišovská 31, 37005 České Budějovice, Czech Republic. Phone: +420 38777 5432; Fax: +420 38531 0388; E-mail: moravec@paru.cas.cz 

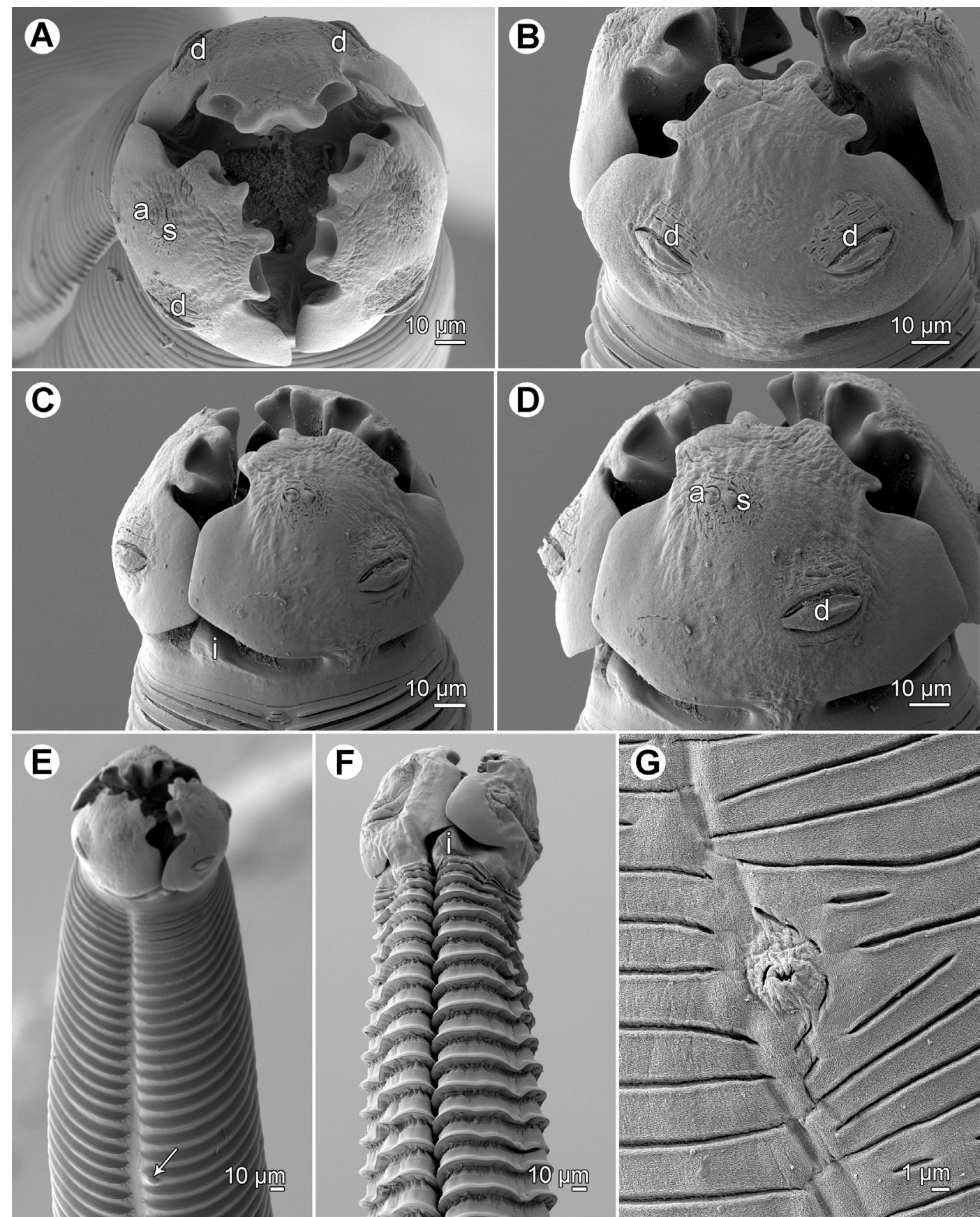

Fig. 2. Iheringascaris inquies (Linton, 1901), scanning electron micrographs of male. A - cephalic end, apical view; B - dorsal lip; C - cephalic end, lateral view; D - subventral lip; $\mathbf{E}$ - anterior end of body, lateral view (arrow indicates deirid); F - same, sublateral view (different specimen); G - excretory pore, ventral view. Abbreviations: a - amphid; d - double cephalic papilla; i - interlabium; $\mathrm{s}-$ single cephalic papilla.

sites. A subsample of 73 mostly immature specimens of I. inquies were recovered from the mesentery in the abdominal cavity of this fish, but the material also included several males and non-gravid females from the digestive tract. The largest male was $29.38 \mathrm{~mm}$ long and $462 \mu \mathrm{m}$ wide and its spicules measured $6.05 \mathrm{~mm}$ ( $20.6 \%$ of the body length), largest females were $18.44-29.76 \mathrm{~mm}$ long and $367-381 \mu \mathrm{m}$ wide, and the general morphology was more or less in accordance with the redescription of I. inquies given by Deardorff and Overstreet (1981).
Since no American specimens of this species have so far been studied using scanning electron microscopy (SEM), and only a few SEM micrographs of I. inquies from a geographically remote area (Australia), with respect to most records of this species, have been published (Bruce and Cannon 1989), the four largest males and the two largest females of the present material were examined using SEM. Specimens were fixed in hot $4 \%$ formaldehyde solution; those used for SEM were postfixed in $1 \%$ osmium tetroxide (in phosphate buffer), dehydrated through 

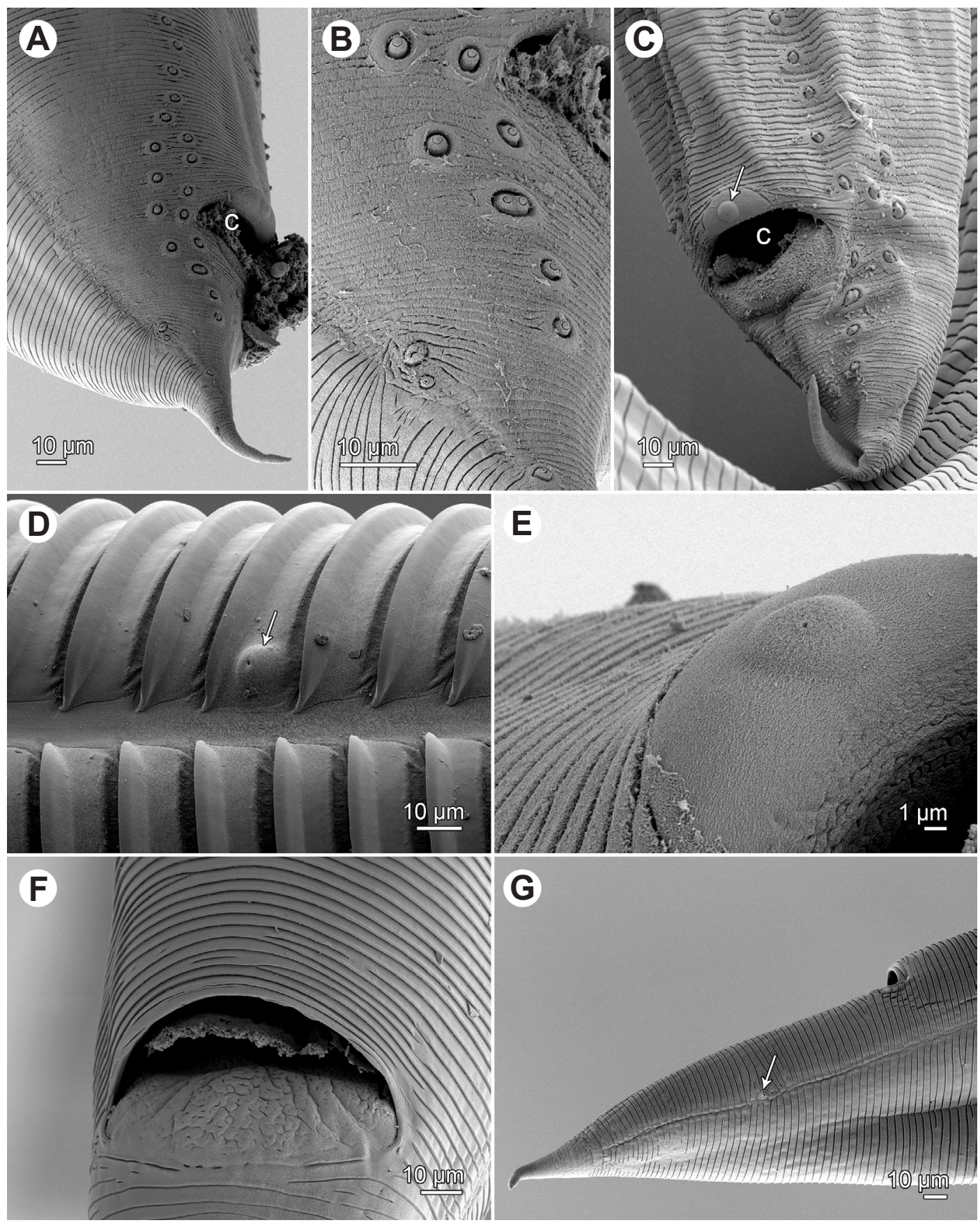

Fig. 3. Iheringascaris inquies (Linton, 1901), scanning electron micrographs. A - posterior end of male, lateral view; B - distribution of adanal and postanal papillae; $\mathbf{C}$ - posterior end of male, subventral view (arrow indicates median preanal papilla); $\mathbf{D}$ - cuticular annulations in region of deirid, lateral view (arrow indicates deirid); $\mathbf{E}$ - median preanal papilla on anterior cloacal lip, sublateral view; $\mathbf{F}$ - anus of female, ventral view; $\mathbf{G}$ - tail of female, lateral view (arrow indicates phasmid). Abbreviation: c - cloacal aperture.

a graded acetone series, critical-point-dried, sputter-coated with gold, and examined using a JEOL JSM-7401F scanning electron microscope at an accelerating voltage of $4 \mathrm{kV}$ (GB low mode).

The present SEM examination of I. inquies made it possible to study in detail some important morphological characters for the first time, especially the distribution of male caudal papillae, which is one of the main features distinguishing Iheringascaris from Hysterothylacium (see above). Whereas Deardorff and Overstreet (1981) reported a total of 37-41 pairs of papil- lae, there were only 33 pairs in the present specimens (the same number as reported by Rasheed 1965). As in most ascaridoid nematodes, there is, apparently, considerable intraspecific variability in the number of pairs of preanal papillae in this species.

The present study confirms that in the region of cloacal aperture the papillae are arranged in two longitudinal rows on each side, one subventral and one more lateral; however, the SEM micrographs show clearly that the numbers and distribution of papillae in the cloacal region and on the tail differ somewhat 
from previously published data (these papillae are very small and can be reliably studied only by SEM). As can be seen in Figs. 1 and $3 \mathrm{~A}-\mathrm{C}$, the male posterior end bears 23 pairs of preanal, two pairs of adanal and eight pairs of postanal papillae; the distribution of adanal and postanal papillae is clearly visible in Fig. 3B (papillae of the second subventral pair of postanals are double). The unpaired median preanal papilla is well developed, being situated on a smooth area on the anterior cloacal lip (Fig. 3C, E). The surfaces of the posterior cloacal lip in the male (Fig. 3B) and of the posterior anal lip in the female (Fig. 3F) are distinctly ridged.

In the diagnosis of Iheringascaris, Deardorff and Overstreet (1981) stated that cuticular alae are present, but in the redescription of I. inquies in the same paper they mention that the lateral alae are extremely reduced or absent in adults. The present SEM study shows that no lateral alae are present in adults of I. inquies and that they are, in fact, replaced by narrow lateral longitudinal grooves which extend along the body and divide each cuticular annulation into two hemicircles (Figs. 2E, F, 3G). The deirids are well developed (Figs. 2E, 3D).

As mentioned above, Bruce and Cannon (1989) observed the clearly defined posterior border of the interlabia and lip peduncles of I. inquies, which they considered one of the distinguishing characters between Iheringascaris and Hysterothylacium. However, this has not been confirmed by the present SEM study of North American specimens, in which the posterior ends of interlabia and lip peduncles are smoothly continuous with the cuticle of the body (Fig. 2B-D). These differences may be due to different methods of fixation, although it cannot be excluded that the parasite populations from such remote geographical areas differ genetically, as mentioned by Bruce and Cannon
(1989). The structure of lips in specimens of the present material (Fig. 2A-F) is similar to that illustrated by both Deardorff and Overstreet (1981) and Bruce and Cannon (1989).

Until recently, Iheringascaris was a monotypic genus represented only by its type species, I. inquies. However, based on the characteristic structure of cuticular annulations on the body, Moravec et al. (2012) provisionally assigned to this genus $I$. neocornuta (Rajyalaksmi, Rao et Shyamasundari, 1992) - species inquirenda, and I. japonica (Rajyalakshmi, 1996) - species inquirenda, two poorly described species from the freshwater eel Anguilla bicolor bicolor McClelland and the marine fish Notopterus japonicus (Bloch), respectively, in Indian waters (Rajyalakhsmi et al. 1992, Rajyalakhsmi 1996). An additional species of Iheringascaris, I. goai Malhotra, Jaiswal, Malakar, Verma, Singh, Lakra, Malhotra et Shamsi, 2012, has recently been described from the perciform fish Sillago sihama (Forsskål) (Sillaginidae) and the siluriform fish Arius maculatus (Thungberg) (Ariidae) off the western coast of India (Malhotra et al. 2012). However, the presence of dentigerous ridges on the inner margin of lips indicates a generic misidentification. The allocation of all the above-mentioned, poorly described, species from different hosts in Indian waters to Iheringascaris needs to be verified.

Acknowledgements. Thanks are due to the staff of the Laboratory of Electron Microscopy, Institute of Parasitology, BC ASCR, in České Budějovice for their technical assistance, and to Blanka Škoríková of the same Institute for the help with the illustrations. This study was partly supported by the Institute of Parasitology (with institutional support RVO:60077344) and the Czech Science Foundation (project No. P505/12/G112).

\section{References}

BRUCE N.L., CANNON L.R.G. 1989: Hysterothylacium, Iheringascaris and Maricostula new genus, nematodes (Ascaridoidea) from Australian pelagic marine fishes. J. Nat. Hist. 23: 13971441.

Deardorff T.L., Overstreet R.M. 1981: Review of Hysterothylacium and Iheringascaris (both previously $=$ Thynnascaris) (Nematoda: Anisakidae) from the northern Gulf of Mexico. Proc. Biol. Soc. Wash. 93 (1980): 1035-1079.

Hartwich G. 1974: Keys to genera of the Ascaridoidea. In: R.C. Anderson, A.G. Chabaud and S. Willmott (Eds.), CIH Keys to the Nematode Parasites of Vertebrates. No. 2. Commonwealth Agricult. Bureaux, Farnham Royal, UK, iv +15 pp.

Linton E. 1901: Parasites of fishes of the Woods Hole region. Bull. U.S. Fish Comm. 19 (1899): 405-492.

Malhotra A., Jaiswal N., Malakar A.K., Verma M.S., Singh H.R., Lakra W.S., Malhotra S.K., Shamsi S. 2012: The morphology and genetic characterization of Iheringascaris goai n. sp. (Nematoda: Raphidascarididae) from the intestine of the silver whiting and spotted catfish off the central west coast of India. J. Helminthol. 86: 353-362.

Moravec F., Taraschewski H., Appelhoff D., Weyl O. 2012: A new species of Hysterothylacium (Nematoda: Anisakidae)

from the giant mottled eel Anguilla marmorata in South Africa. Helminthologia 49: 174-180.

Mozgovoy A.A. 1953: [Ascaridata of Animals and Man and the Diseases Caused by Them. Essentials of Nematodology 2.] Publ. House of the USSR Acad. Sci., Moscow, 616 pp. (In Russian.)

Rajyalakshmi I. 1996: Description of a new species of Hysterothylacium Ward and Magath, 1917 (Nematoda: Anisakidae) from the intestine of marine fish, Nemipterus japonicus (Bloch). Riv. Parassitol. 8: 53-60.

Rajyalakshmi I., Rao H.K., Shyamasundari K. 1992: Hysterothylacium neocornutum n. sp. (Nematoda: Anisakidae) from the freshwater fish, Anguilla bicolor bicolor McClelland of Godavari river (Rajahmundry). Riv. Parassitol. 9: 147-159.

RASHeEd S. 1965: On a remarkable new nematode, Lappetascaris lutjani gen. et sp. nov. (Anisakidae: Ascaridoidea) from marine fishes of Karachi and an account of Thynnascaris inquies (Linton, 1901) n. comb. and Goezia intermedia n. sp. J. Helminthol. 39: $313-342$.

Received 30 July 2012

Accepted 30 August 2012 